\title{
ESTUDO ADSORTIVO DO CORANTE ALARANJADO DE METILA EM CARVÕES ATIVADOS OBTIDOS A PARTIR DE RESÍDUOS DA AGROINDÚSTRIA
}

\author{
J. G. PIMENTEL ${ }^{1 *}$, W. L. S. MACIEL ${ }^{1}$; N. M. da SILVA ${ }^{1}$; R. V. ARAÚJO ${ }^{1}$; C. M. VELOSO ${ }^{2}$; R. \\ C. F. BONOMO ${ }^{3}$ \\ ${ }^{1}$ Universidade Estadual do Sudoeste da Bahia, Laboratório de Engenharia de Processos \\ ${ }^{5}$ Universidade Estadual do Sudoeste da Bahia, Departamento de Ciências Naturais \\ ${ }^{6}$ Universidade Estadual do Sudoeste da Bahia, Departamento de Tecnologia Rural e Animal \\ *e-mail: juliana.eng@outlook.com
}

\begin{abstract}
RESUMO
Diversos métodos estão sendo desenvolvidos para eliminar os corantes presentes em efluentes, entre os quais está a adsorção. Este trabalho deve como objetivo estudar a eficiência de carvões ativados obtidos a partir de resíduos da agroindústria no processo de adsorção de corantes presentes em efluente industriais, utilizando como molécula modelo o alaranjado de metila. Foi realizado um estudo da massa ideal para conduzir o processo adsortivo determinando a eficiência e a capacidade adsortiva, utilizou-se diferentes valores de massas dos carvões, diluídas em solução do corante em pH 7,0 e concentração de 500 ppm. Em seguida, os tubos com a solução foram conduzidos para um aparato experimental em condições de agitação constante e temperatura ambiente por um período de $24 \mathrm{~h}$. Obtendo a massa ideal de $13 \mathrm{mg}$ para o carvão de casca de cacau e $11 \mathrm{mg}$ para o carvão proveniente do caroço de siriguela.
\end{abstract}

\section{INTRODUÇÃo}

A grande quantidade de água e corantes utilizados nos processos das indústrias têxteis gera um volume significativo de efluente colorido, causando problemas ao meio ambiente principalmente quando descartado sem tratamento (CORREIA, STEPHENSON \& JUDD 1994; MEIER e MATTJIE, 2011).

No Brasil, das aproximadamente 20 t/ano de corantes consumidos pela indústria têxtil, cerca de $20 \%$ são descartados como efluentes. A principal fonte desta perda corresponde à fixação incompleta dos corantes à fibra durante o processo de tingimento (GUARATINI \& ZANONI, 2000; ZANONI \& CARNEIRO, 2001); gerando, por conseguinte, um dos tipos de resíduos que mais traz problemas ao meio ambiente.
Do ponto de vista ambiental, a remoção de corantes sintéticos dos efluentes é um dos grandes problemas enfrentados pelas industriais que se enquadram nesse setor e possuem tamanho interesse, já que os corantes apresentam eleva a carga tóxica, além de poder acarretar doenças carcierígenas e mutações nas espécies ao longo do tempo.

Devido à complexa constituição química e variedade desses corantes, visto que existem disponíveis nesta indústria, mais de 100 mil corantes comerciais, sendo que cerca de 2 mil para a indústria têxtil (HARTMANN, 2005), tratamentos convencionais, físico-químicos quanto biológicos, além de dispendiosos custos, não são eficientes na remoção desses corantes. Uma grande necessidade de técnicas de separação eficientes e econômicas em larga escala, com rendimento de recuperação, sem 
degradar a molécula alvo da separação, estão em vista.

A adsorção devido à sua importância científica e tecnológica, com aplicação em muitas áreas, vem sendo uma alternativa eficiente para remoção de corante e tratamento de efluentes. É um fenômeno físico-químico onde o componente em fase líquida é transferido para a superfície de uma fase sólida. Os componentes que se unem à superfície são chamados adsorvatos, enquanto que a fase sólida que retém o adsorvato é chamada adsorvente. (MASEL, 1996).

A migração dos componentes em fase líquida de uma fase para outra tem como força motriz a diferença de concentrações entre $o$ seio do fluido e a superfície do adsorvente. Usualmente o adsorvente é composto de partículas que são empacotadas em um leito fixo por onde passa a fase fluida continuamente até que não haja mais transferência de massa. Como o adsorvato concentra-se na superfície do adsorvente, quanto maior for esta superfície, maior será a eficiência da adsorção. Por isso, geralmente os adsorventes são sólidos com partículas porosas (BORBA, 2006).

$\mathrm{O}$ adsorvente mais utilizado em escala industrial é o carvão ativado (CA), considerado como um bom adsorvente para remoção de poluentes, tanto corantes quanto metais pesados (SATHISHKUMAR et al., 2012; MEIER et al., 2011). Uma alternativa para produção de carvões ativados é a utilização de resíduos carbonáceos que podem ser reciclados e usados como adsorventes de baixo custo e, para este fim, diversos resíduos orgânicos $\mathrm{e}$ industriais tem sido testado (SANGHI e BHATTACHARYA, 2002). Como exemplos desses tipos de resíduos orgânicos podem ser citados: caroço de siriguela, casca de cacau, mesocarpo do coco, bagaço de cana, entre outros.

Diante do exposto o objetivo, deste, foi conduzir ensaios adsortivos para determinar a massa ideal dos carvões obtidos a partir dos resíduos da casca do cacau e do caroço de siriguela, utilizando como molécula modelo o corante Alaranjado de Metila.

\section{MATERIAL E MÉTODOS}

O experimento foi realizado no Laboratório de Engenharia de Processos (LEP) da Universidade Estadual do Sudoeste da Bahia (UESB), no campus Juvino Oliveira.

\subsection{Obtenção dos Carvões Ativados}

As matérias-primas oriundas da casca de cacau e caroço de siriguela foram obtidas e passadas e em seguidas submetidas à secagem natural durante $24 \mathrm{~h}$ e secagem em estufa (Tecnal TE 393/1) com circulação de ar à temperatura de $105^{\circ} \mathrm{C}$ por $24 \mathrm{~h}$; depois todo o material seco foi triturado em moinho de facas, tamisado para selecionar a granulometria de 40 mesh e armazenado para o uso posterior.

Em seguida os precursores passaram por uma ativação sendo utilizado como agente de ativação, o cloreto de zinco para os ambos os carvões. A impregnação com cloreto de zinco (Merck, 98\%) realizou-se do seguinte modo: adicionando $1 \mathrm{~g}$ de agente: $2 \mathrm{~g}$ de precursor (resíduo), sob agitação manual, por cerca de $30 \mathrm{~min}$ e em seguida tratado termicamente em estufa a $110{ }^{\circ} \mathrm{C}$ por $24 \mathrm{~h}$. A carbonização do material foi realizada em forno mufla (Vulcan 3-550) sob fluxo de nitrogênio, com taxa de aquecimento de 5 ${ }^{\circ} \mathrm{C} . \mathrm{min}^{-1}$, a $500{ }^{\circ} \mathrm{C}$ por $40 \mathrm{~min}$. O carvão obtido foi imerso em uma solução de ácido clorídrico (Qhemis, 37\%) por 20 min e lavado com água destilada até que o $\mathrm{pH}$ neutro fosse alcançado. Em seguida o material foi seco em estufa à $80{ }^{\circ} \mathrm{C}$ por $8 \mathrm{~h}$ e armazenagem em embalagem hermeticamente fechada.

Após a ativação dos carvões, os mesmos foram codificados e separados do seguinte modo: CTZ, Carvão de casca de cacau (Theobroma cocoa L.) ativado com $\mathrm{ZnCl}_{2}$ e; CSZ, Carvão do caroço de siriguela 
(Spondias purpurea L.) ativado também com $\mathrm{ZnCl}_{2}$

\subsection{Quantificação do Adsorvato}

O corante utilizado no processo de adsorção foi o Alaranjado de Metila (Nuclear), obtido comercialmente, e utilizouse como adsorvente os carvões de siriguela e de cacau, mencionados anteriormente.

Para quantificar o alaranjado de metila utilizou-se uma curva padrão obtida pelo método espectrofotométrico com leitura direta em comprimento de onda de $462 \mathrm{~nm}$. A curva de calibração foi construída a partir de soluções de alaranjado de metila em água destilada com concentrações definidas em 2 mg.L ${ }^{-1}, 4$ mg. $L^{-1}, 6$ mg. $L^{-1}, 8$ mg.L $L^{-1}, 10$ mg. $\mathrm{L}^{-1}, 12 \mathrm{mg} . \mathrm{L}^{-1}$ e $14 \mathrm{mg} . \mathrm{L}^{-1}$.

\subsection{Estudo de Massa e Capacidade Adsorvita}

Visando obter um valor exato da massa de adsorvente na eficiência de adsorção para cada um dos dois tipos de carvões analisados, cinco valores de massas dos carvões foram testados: $5 \mathrm{mg}$; $10 \mathrm{mg} ; 15 \mathrm{mg}$; $25 \mathrm{mg} ; 40 \mathrm{mg}$, adicionadas em tubos contendo $5 \mathrm{~mL}$ da solução do Alaranjado de Metila com concentração inicial de 500 ppm em $\mathrm{pH}$ neutro. Os tubos foram mantidos sob agitação constante, em um aparato experimental, em temperatura ambiente por um período de $24 \mathrm{~h}$ e em seguida a solução foi centrifugada (Centrífuga MPW-350). O sobrenadante foi filtrado, utilizando filtro de seringa de PTFE hidrofílico, poro $0,45 \mu \mathrm{m}$, diâmetro do filtro $25 \mathrm{~mm}$ (Analítica) e, em seguida, foi feita a quantificação do corante remanescente por leitura direta em espectrofotômetro (Biochrom Libra S70).

A partir dos valores de absorbância das soluções lidos no espectrofotômetro e da curva de calibração, determinou-se a capacidade adsortiva de cada um dos carvões, utilizando a Equação 1.

$$
q_{e q}=\frac{V C_{i n}-V C_{e q}}{m_{a d s}}
$$

Onde: qeq é a capacidade adsortiva (mg.g $\left.{ }^{-1}\right), \mathrm{V}$ é o volume de solução $(\mathrm{mL}), \mathrm{C}_{\text {in }}$ concentração inicial da solução $\left(\mathrm{mg} . \mathrm{L}^{-1}\right), \mathrm{C}_{\mathrm{eq}}$ é a concentração final da solução $\left(\mathrm{mg} . \mathrm{L}^{-1}\right)$ e $\mathrm{m}_{\mathrm{ads}}$ é a massa do adsorvente (g).

A eficiência do processo adsortivo foi obtida a partir dos valores de concentração inicial e final da solução, conforme a Equação 2.

$$
\text { efic }=\left(\frac{V C_{i n}-V C_{e q}}{V C_{i n}}\right) \times 100
$$

Onde: efic é a eficiência da adsorção (\%), V é o volume de solução $(\mathrm{mL}), \mathrm{C}_{\text {in }}$ concentração inicial da solução $\left(\mathrm{mg} . \mathrm{L}^{-1}\right)$ e $\mathrm{C}_{\mathrm{eq}}$ é a concentração de saída da solução $\left(\mathrm{mg} \cdot \mathrm{L}^{-1}\right)$.

Os gráficos de estudo de massa foram plotados no software SigmaPlot 11.0.

\subsection{Caracterização Textural dos Carvões}

A estrutura porosa dos carvões ativados (CSZ e CTZ) foi determinada por adsorção de $\mathrm{N}_{2}$ a $77 \mathrm{~K}$ em um equipamento ASAP 2010 (Micromeritics). Antes das medidas, a amostra foi submetida a uma etapa de pré-tratamento. Posteriormente foi obtida a isoterma de adsorção e dessorção de nitrogênio a 77 K. A área superficial específica foi determinada pela equação de BET. A distribuição de poros foi obtida a partir da isoterma de dessorção utilizando o método BJH.

\section{RESULTADOS E DISCUSSÕES}

O estudo de massa realizado para o corante aniônico Alaranjado de Metila com os dois tipos de carvão ativados testados estão apresentados nas Figuras 1 e 2, respectivamente.

Segundo Nunes (2009), os extremos avaliados num estudo de massa apresentam baixa eficiência como parâmetro operacional 
por questões antagônicas. Quando se utiliza pequenas massas de material adsorvente, este sofre uma rápida saturação, por adsorver uma elevada quantidade de adsorvato por grama de material. Isso resulta num elevado valor de q, contudo não é suficiente para obter uma eficiência de extração satisfatória que justifique a condição operacional. No outro extremo, quando aplicada uma elevada massa de material adsorvente, apesar de atingir uma extração satisfatória, o carvão ativado é subaproveitado (baixo q), o que poderia elevar o custo operacional do processo. Então, o ponto onde as curvas de eficiência e capacidade adsortiva se encontram dará a massa de carvão ativado que deverá ser utilizada nos processos de adsorção.

Dessa forma, para o corante em estudo (Figura 1), a massa ideal foi de $13 \mathrm{mg}$, aproximadamente, do CTZ - Carvão de casca de cacau (Theobroma cocoa L.), que está associada a uma eficiência em torno de $80 \%$.

Figura 1. Eficiência de extração e capacidade adsortiva do corante Alaranjado de Metila no carvão (CTZ).

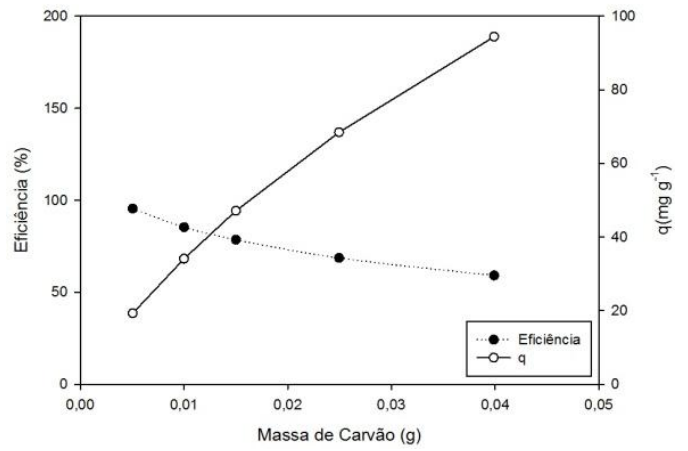

Fonte: SigmaPlot 11.0; J.G. PIMENTEL (2015)

Já para o CSZ, Carvão do caroço de siriguela (Spondias purpurea L.), em análise, para o corante em estudo (Figura 2) a massa ideal foi de $11 \mathrm{mg}$, aproximadamente, do carvão em estudo estando associada a uma eficiência em torno de $82 \%$.

Figura 2. Eficiência de extração e capacidade adsortiva do corante Alaranjado de Metila no carvão (CSZ).

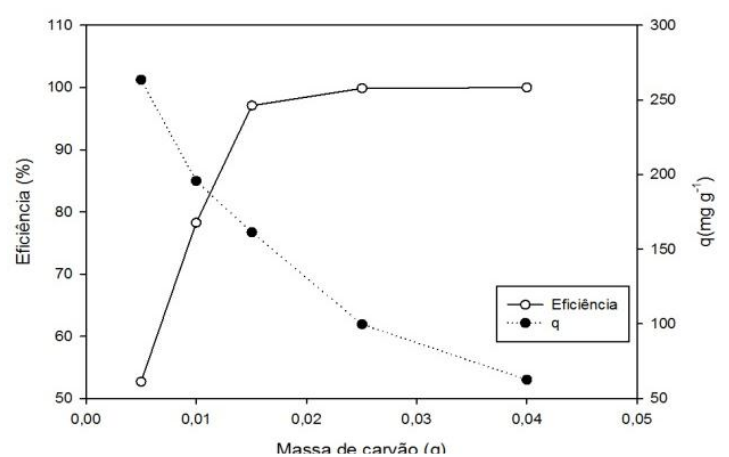

Fonte: SigmaPlot 11.0; J.G. PIMENTEL (2015)

Os elevados valores de eficiência e capacidade adsortiva observados para o processo de adsorção nos carvões ativados utilizados estão relacionados às suas características texturais, mostrados na Tabela 1. Ambos os carvões apresentaram área superficial e volume de poros elevados. Além disso, o tamanho dos poros é superior ao tamanho da molécula do alaranjado de metila.

Tabela 1. Caracterização textural dos carvões obtidos a partir do resíduo do caroço de siriguela e da casca de cacau.

\begin{tabular}{cccc}
\hline Amostra & $\begin{array}{c}\text { Área } \\
\text { Superficial } \\
\left(\mathrm{m}^{2} \cdot \mathrm{g}^{-1}\right)\end{array}$ & $\begin{array}{c}\text { Volume } \\
\text { de poros } \\
\left(\mathrm{cm}^{3} \cdot \mathrm{g}^{-}\right.\end{array}$ & $\begin{array}{c}\text { Diâmetro } \\
(\mathrm{A})\end{array}$ \\
\hline CTZ & 642 & 0,37 & 23 \\
CSZ & 956 & 0,48 & 20
\end{tabular}

Fonte: Pereira et al. (2014)

Devido aos valores mais elevados da área superficial e de volume de poros do CSZ, observa-se que mesmo utilizando massas aproximadamente iguais das duas amostras, obtêm-se uma capacidade adsortiva bem superior para esse carvão. Esse comportamento pode ser explicado levandose em consideração que a capacidade adsortiva é a relação entre a massa do adsorbato em (mg) e a massa do adsorvente em (g). Com uma área superior mais sítios 
estão presentes na superfície do carvão para adsorver as moléculas do corante.

\section{CONCLUSÃO}

Com os resultados obtidos através desta pesquisa, e mostrados neste presente trabalho, pode-se concluir que os carvões produzidos a partir do caroço de siriguela (Spondias purpúrea L), CSZ, e da casca de cacau (Theobroma cocoa L.), CTZ; apresentaram boa capacidade de adsorção com excelentes resultados de eficiência para o corante de estudo presente em solução aquosa. A baixa massa dos carvões necessária para tais efeitos revela assim a viabilidades para o uso industrial dos mesmos. Contudo, outras análises fazem-se necessárias para concretizar aplicação efetiva dessa técnica de tratamento nos efluentes têxteis.

\section{REFERÊNCIAS}

BORBA, C. E. Modelagem da remoção de metais pesados em coluna de adsorção de leito fixo. Dissertação Mestrado. Faculdade de Engenharia Química, Universidade Estadual de Campinas, 145p, 2006.

CORREIA, V. M.; STEPHENSON, T.; JUDD, S. Characterisation of textile wastewaters - a review.Environmental Technology, vol. 15, p. 917-929, 1994.

GUARATINI, C. C. I. e ZANONI, M. V. B. Corantes Têxteis, Química Nova, v. 23, n. 1, p. 71-78, 2000.

HARTMANN, M. Ordered Mesoporous Materials for Bioadsorption and Biocatalysis. Chemistry of Materials. v. 17, p. 4577-4593, 2005.

MASEL, R. I. Principles of Adsorption and reaction on solid surfaces, John Wiley \& Sons Inc., p. 112, 1996.
MEIER, T. R. W., MATTJIE. A. C., Remoção de corantes têxteis por adsorção utilizando carvão ativado obtidos de materiais não convencionais. Anais do III ENDICT. 2011.

NUNES, D.L Preparação de Carvão Ativado a partir de torta prensada de Raphanus sativus L. e utilização para clarificação de soluções. Dissertação de Mestrado. Faculdade de Farmácia da Universidade Federal de Minas Gerais, 117p, 2009.

PEREIRA, R. G, et al. Preparation of activated carbons from cocoa shells and siriguela seeds using H3PO4 and ZnCL2 as activating agents for BSA and $\alpha$ lactalbumin adsorption. Fuel Processing Technology, v.126, p. 476-486, 2014.

SANGUI, R., BHATTACHARYA. Review on decolorisation of aqueous dye solutions by low cost adsorbents. Colorantion Technology, v.118, p. 256-269, 2002.

SATHISHKUMAR et al. Utilization of agroindustrial waste jatrophacurcas pods as an activated carbon for the adsorption of reactive dye Remazol Brilliant Blue $R$ (RBBR), v.22, p. 67-75, 2011.

ZANONI, M. V. B.; CARNEIRO, P. A. O descarte dos corantes têxteis. Ciência Hoje, v. 29, n. 174, p. 61-64, 2001.

\section{AGRADECIMENTOS}

Foi imprescindível às oportunidades concedidas na unidade de ensino, UESB, através da bolsa de iniciação voluntária, e ao Laboratório de Engenharia de Processos (LEP) podem ser realizadas todas as análises. 